\title{
What colour are your eyes? Teaching the genetics of eye colour \& colour vision. Edridge Green Lecture RCOphth Annual Congress Glasgow May 2019
}

\author{
David A. Mackey iD ${ }^{1,2}$ 约 \\ (c) The Author(s) 2021
}

\begin{abstract}
Eye colour and colour perception are excellent examples to use when teaching genetics as they encompass not simply the basic Mendelian genetics of dominant, recessive and X-linked disorders, but also many of the new concepts such as non-allelic diseases, polygenic disease, phenocopies, genome-wide association study (GWAS), founder effects, gene-environment interaction, evolutionary drivers for variations, copy number variation, insertions deletions, methylation and gene inactivation. Beyond genetics, colour perception touches on concepts involving optics, physics, physiology and psychology and can capture the imagination of the population, as we saw with social media trend of "\#the dress". Television shows such as Game of Thrones focused attention on the eye colour of characters, as well as their Dire-wolves and Dragons. These themes in popular culture can be leveraged as tools to teach and engage everyone in genetics, which is now a key component in all eye diseases. As the explosion of data from genomics, big data and artificial intelligence transforms medicine, ophthalmologists need to be genetically literate. Genetics is relevant, not just for Inherited Retinal Diseases and congenital abnormalities but also for the leading causes of blindness: age-related macular degeneration, glaucoma, myopia, diabetic retinopathy and cataract. Genetics should be part of the armamentarium of every practicing ophthalmologist. We need to ask every patient about their family history. In the near future, patients will attend eye clinics with genetic results showing they are at high risk of certain eye diseases and ophthalmologists will need to know how to screen, follow and treat these patients.
\end{abstract}

Eye (2022) 36:704-715; https://doi.org/10.1038/s41433-021-01749-x

\section{INTRODUCTION}

Eye colour, or more correctly iris colour, is often used as an example for teaching Mendelian genetics, with brown being dominant and blue being recessive. Colour blindness "Daltonism", which affects $8 \%$ of the male population, is a leading example for teaching X-linked recessive disease (Fig. 1). This simple model works well most of the time, with the main blue eye gene OCA2. We can draw pedigrees showing homozygote blue- and homozygote brown-eyed parents having heterozygote brown-eyed children and then grandchildren who may be homozygote or hererozygote blue- or brown-eyed depending on their other parent (Fig. 2).

Blue or brown describes only a portion of eye colour. There are intermediate variations of green and hazel, as well as albino eyes, which lack pigment entirely-all examples for which the simple Mendelian model does not apply. Geneticist Victor McKusick stated, "The early view that blue is a simple recessive has been repeatedly shown to be wrong by observation of brown-eyed offspring of two blue-eyed parents" [1]. This may have inspired his own interest in genetics, as he and his identical twin brother had brown eyes and their parents had blue! We now know that eye colour is actually a complex genetic trait, involving interaction of some major genes and many minor genes. This MendelianComplex genetic explanation for eye colour also crosses over into the genetics of many other eye diseases such as age-related macular degeneration and glaucoma. Many people can look at the eye colours in their own families and draw their own pedigrees to see how the Mendelian model applies. Individuals of Asian or African ancestry, most of whom have brown eyes, can still look at other families. Capturing the attention of the public with eye colour and genealogies was done marvellously by the TV series (and books) of Game of Thrones. Viewers tried to predict events based on eye colour, "I see a darkness in you. And in that darkness, eyes staring back at me. Brown eyes, blue eyes, green eyes. Eyes you'll shut forever. We will meet again." Melisandre. Game of Thrones season 3 .

\section{MORE THAN JUST BLUE AND BROWN} Classification of colour

Whilst the Young-Helmholz trichomatic theory of colour vision (now explained by the presence of three different colour opsin genes) suggests we can define all our perceived colours as mixtures of red, blue and green (or with our colour printers using complementary colours: cyan, magenta or yellow), there is no agreed 'definition of eye colour' and there are challenges in consistency of describing colours across different languages and cultures. Researchers of language show that many words for

${ }^{1}$ Lions Eye Institute, University of Western Australia, Perth, WA, Australia. ${ }^{2}$ School of Medicine, University of Tasmania, Hobart, Tas, Australia. ${ }^{凶}$ email: D.Mackey@utas.edu.au 


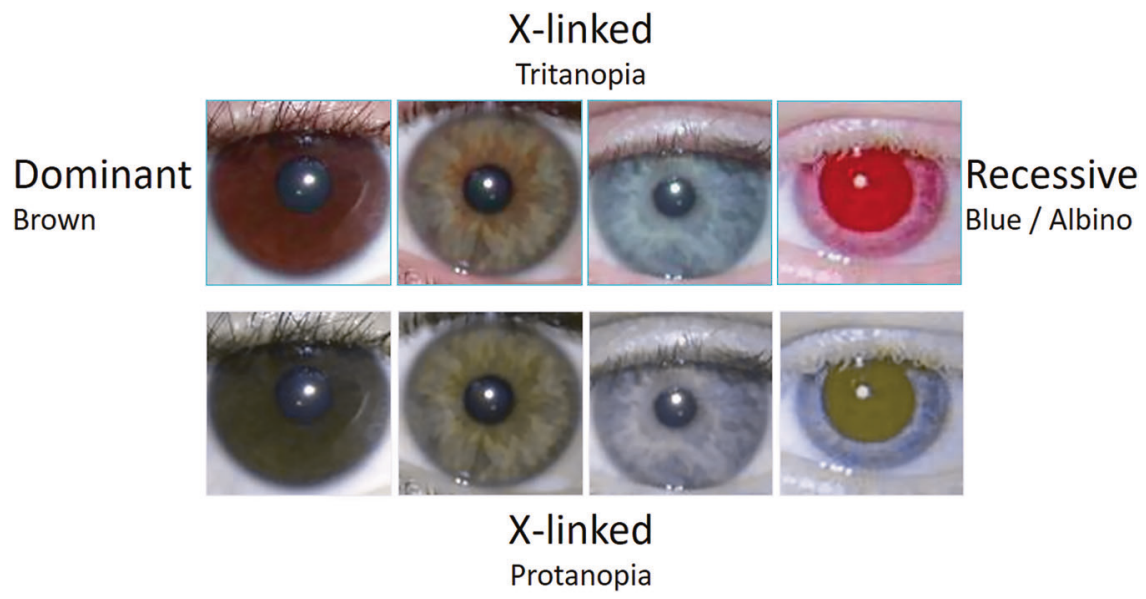

Fig. 1 Basic Mendelian Genetics of Eye Colour and Colour Perception. Upper row: Brown, Hazel/Green, Blue and Albino eyes as seen by most of the tritanopic "normal" population. Lower row: the same eyes as would be perceived by a person with X-linked protanopia.

\section{Recessive Eye Colour}

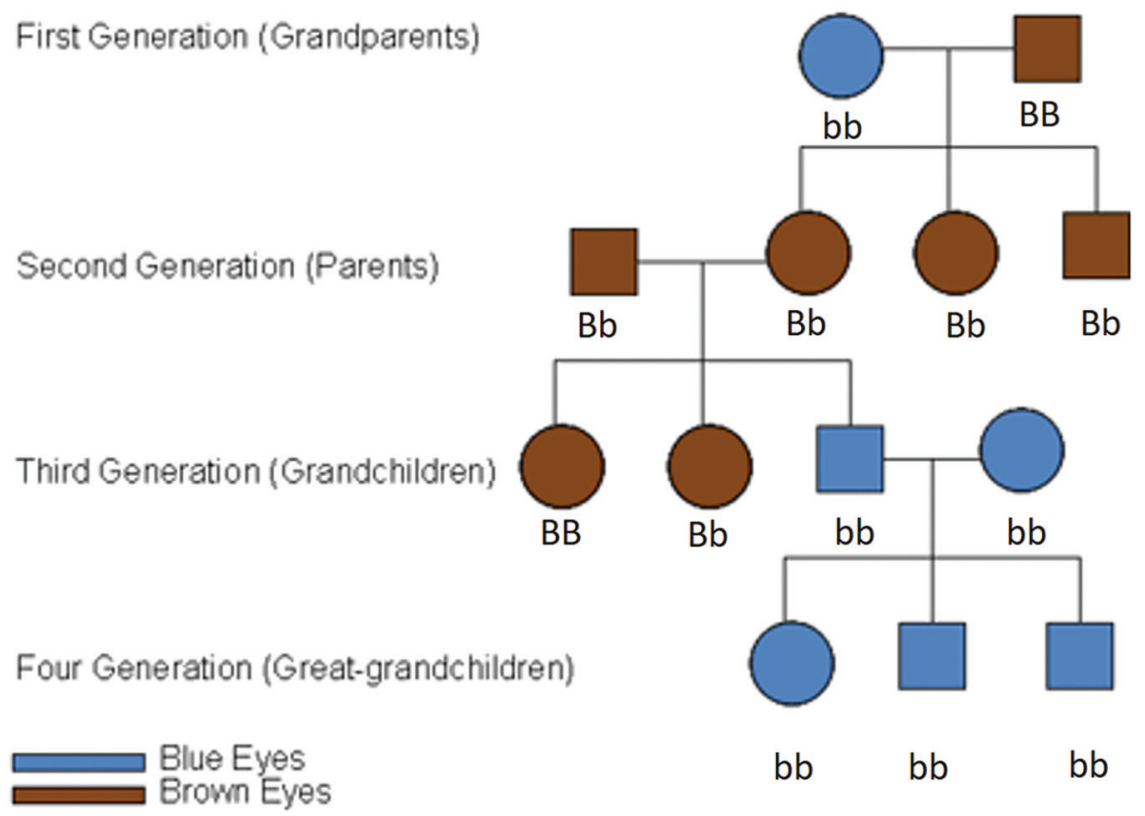

Fig. 2 Simple four-generation Mendelian Pedigree of Brown and Blue eyes. Phenotype shown as brown or blue while dominant brown gene $=\mathrm{B}$ and recessive blue gene $=\mathrm{b}$ Individuals with bb have blue eyes, while individuals with $\mathrm{BB}$ or $\mathrm{Bb}$ have brown eyes.

colour have developed differently, the obvious explanation being the environment that people were living in and the objects that they needed to describe. Berlin and Kay identified 11 possible basic colour categories, starting with white/black, red, green/ yellow, blue, brown, purple/pink/orange/grey [2]. Physicist Isaac Newton even added two colours to the rainbow-orange and indigo-bringing the total to seven (red, orange, yellow, green, blue, indigo, violet) so that the colours would be divided after the manner of a musical chord [3].

"Let there be light" Genesis 1:3. Colour is actually a perception rather than a physical property of light so I ask students, "What colour was the big bang?" As no-one was present at the time to perceive it, there was no colour-in fact visible light did not appear until 380,000 years later. Colour can be described in terms of hue (dominant wavelength of the visible spectrum), saturation (the amount of white light mixed in with a hue) and brightness (intensity of light). Any desired hue of light can be produced when various amounts of the three primary colours of light (red, green and blue (RGB)) are combined, either by addition or by subtraction. In 1931, the International Commission on Illumination (CIE) first defined quantitative links between physical pure colours (i.e. wavelengths) and physiological perceived colours in human colour vision [4]. The CIE 1931 RGB colour space (Fig. 3) and CIE 1931 XYZ colour space encompass all perceived colours. This allows one to translate different physical responses to visible radiation in colour inks, illuminated displays and recording devices such as digital cameras, into a universal human colour-vision response.

We now have several major colour systems, including the World Wide Web HTML colours, which are defined using a hexadecimal notation (HEX) for the combination of RGB colour values [5]. The lowest value that can be given to one of the light sources is 0 (in 
HEX:00) and the highest value is 255 (in HEX:FF). The combination of Red, Green, and Blue values from 0 to 255 gives more than 16 million different colours $(256 \times 256 \times 256)$. There are also commercial colour-matching schemes, such as the Pantone Matching System [6], that list more than 3000 colours for use in a variety of industries, such as design and manufacturing, in physical and digital formats. They describe more than 50 shades of grey.

\section{Classification of eye colour}

Researchers have been classifying eye colour in either French or English since the nineteenth century [7], initially starting with a

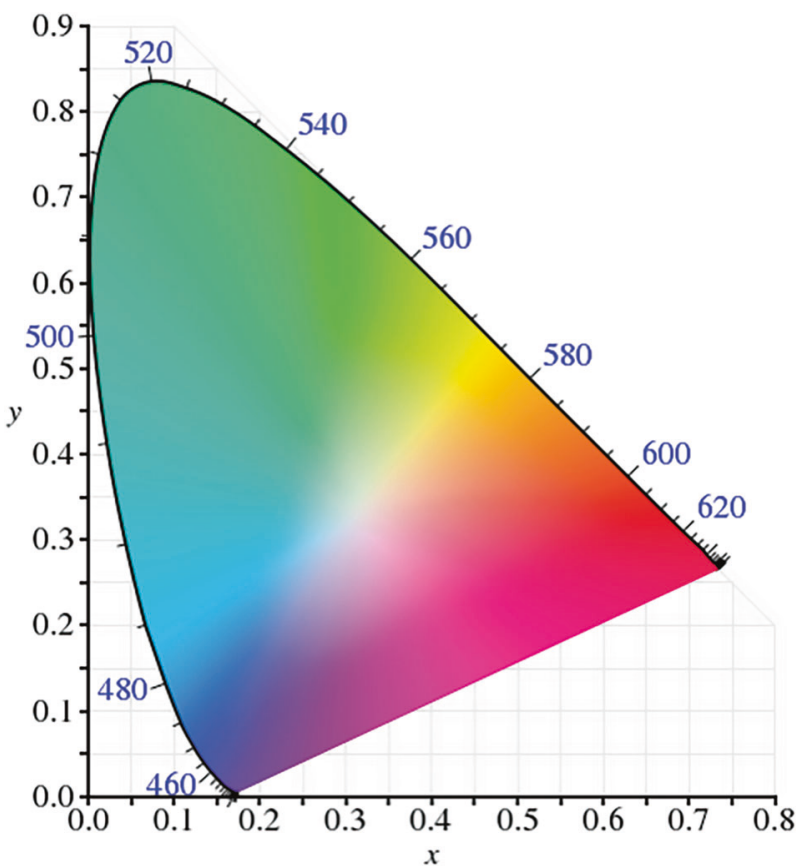

Fig. 3 CIE colour diagram. This shows three arms and the complete perceived spectrum of colours. small subset of categories (Fig. 4 [8-13]) and, in recent decades, moving more fully into computer-generated classifications [14]. In addition to the overall colour of the iris, in some people there is variation in the distribution of the pigment. In the Twins Eye Study in Tasmania, we documented a continuum of green iris with a small ring of brown pigment around the pupil margin, that was wider in some people, extending through to the periphery with brown eyes with a few peripheral green flecks (Fig. 5). In addition, other structural features of the iris can influence eye colour. These include: iris crypt frequency, furrow contractions and iris naevi and these also have genetic influences [15].

\section{Where does blue come from?}

The main pigment in the eye is the dark brown melanin, whilst the scattering of light from the collagen fibres in the sclera make it appear white and the haemoglobin in the blood vessels appears red. Cyanosis is a bluish colour given by high levels of deoxyhaemoglobin in the blood, but this is not related to eye colour. So where does blue come from as there is no blue pigment in the eye? The explanation for why some eyes are blue is the same as why the sky is blue, a phenomenon known as the Tyndall effect. Light is scattered by particles in the atmosphere (or by the opaque layers in the iris) with blue scattered more than red. Blue iris is an example of a structural colour rather than a pigment colour. Brown irises have the same layer with more melanin and appear brown while complete absence of melanin (Albinism), the iris appears red from the red of the retina.

\section{MOVING BEYOND THE SIMPLE MENDELIAN MODEL}

Whilst two parents with blue-green eyes may ponder the genetics of their dark-eyed offspring (Fig. 6), the best example of this apparent breach of Mendelian rules was published in 1952 where two parents with oculo-cutaneous albinism had three normally pigmented offspring. These families can be explained if we consider the formation and deposition of pigment as a multi-step pathway and thus it is possible to be recessive at different steps in the pathway. It is possible that one parent had mutations in the OCA1 (tyrosinase gene) while the other parent had mutations in

\section{Classification of Eye Colour}

- grey, blue, auburn, brown, black

- Pétrequin J. Sur les diverses couleurs de l'iris et leurs proportions dans nos climats. Ann. d'oculistique 1843; 10: 120-5.

- grey, blue, hazel and brown

- Wilde WR. An essay on the malformations and congenital diseases of the organs of sight. Dublin 1862.

- blue (with grey, blue \& green tints) and brown (with yellow, hazel, auburn, light brown, dark brown \& black tints)

- Cornaz E. Recherches statistiques sur la fréquence comparative des couleurs de l'iris. Ann. d'oculistique 1854; 31: 251-80.

- light blue; blue/dark blue; grey/blue-green; dark grey/hazel; light brown; brown; dark brown; black

- Galton F. Family likeness in eye-colour. Proc R Soc Lond 1886; 40: 402-16.

- blue, grey, heterochromic mixed, brown

- Tocher JF. Pigmentation survey of school children in Scotland. Biometrika 1908; 6: 129_ 235.

- pure blue, grey or pale yellow, deep yellow, dark brown or chocolate

- Brownlee J. On inheritance of hair and eye colour. Proc R Soc Edinb 1912; 32: 458-74.

Fig. 4 Some early classifications of eye colour with different subgroups. Colour names shaded to the colour mentioned. 


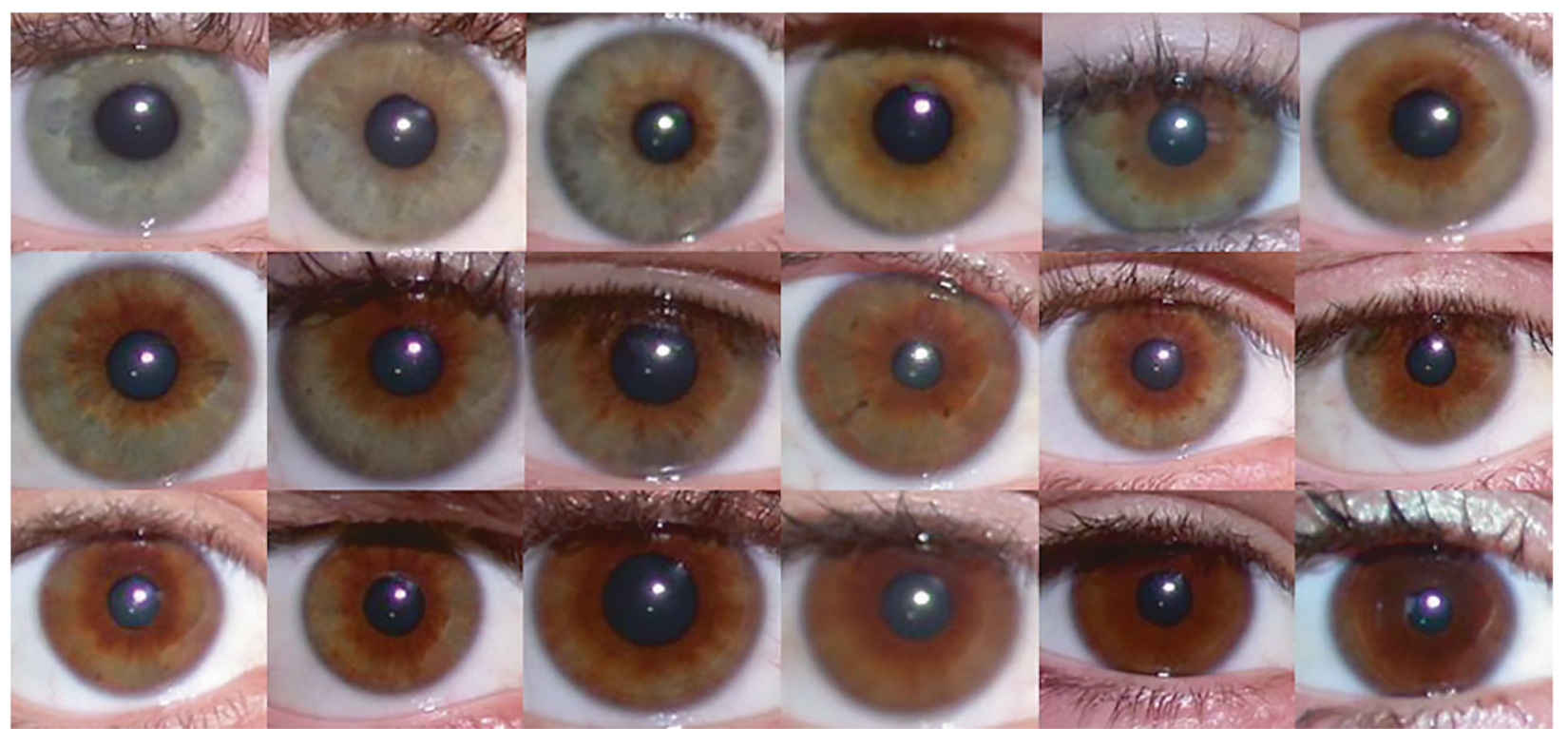

Fig. 5 A series of iris photographs. This shows a continuum of green with brown iris colour, ranging from small pupil ring to almost complete brown with peripheral green flecks.
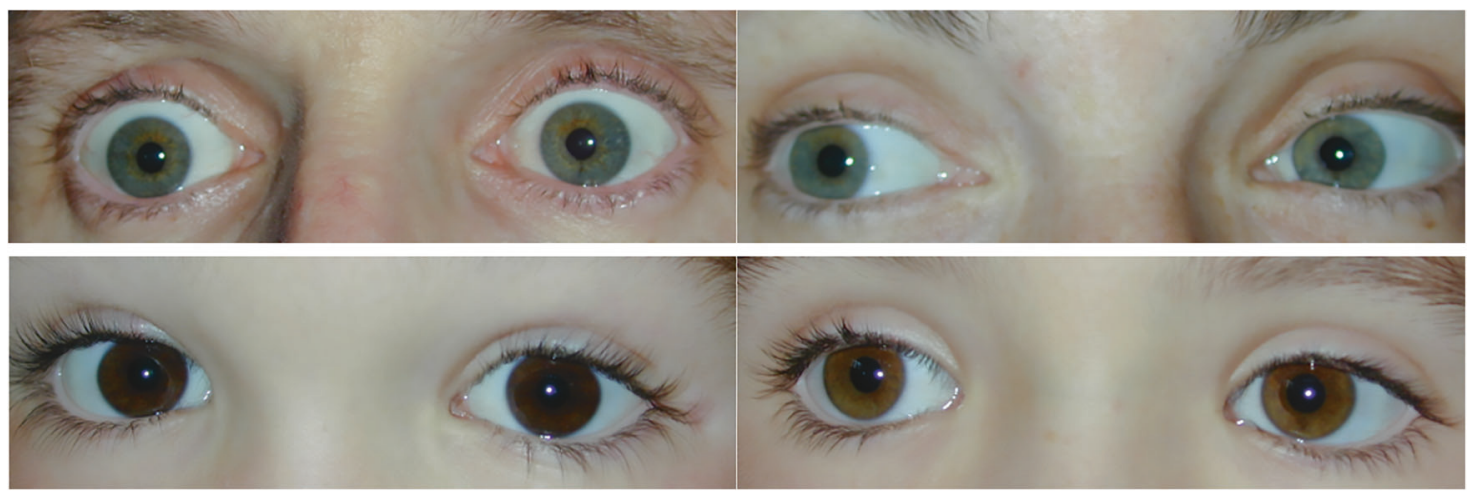

Fig. 6 Iris photos of a family. Parents above with blue-green eyes have two children below with dark brown eyes.

the OCA2 gene (Fig. 7). Seven OCA genes have been identified (and many more known to influence pigment). If parents are recessive at the same gene, then this is called allelic. However, if there are different genes involved in the development of a single character, these are non-allelic. Another clinical example is Leber Congenital Amaurosis, a monogenic disease for which at least 27 different genes are implicated [16]. If two people with different genetic types of recessive LCA had offspring, then the children would be unaffected carriers (although for two different LCA genes).

\section{Eye colour in twins, heritability and linkage analysis}

Research with twins is a powerful tool in determining heritability. Heritability is the proportion of phenotypic variation in a population that is attributable to genetic variation among individuals. Many eye diseases and measures of ocular biometry, including eye colour (Fig. 8), have high heritability [17]. A study of 920 twin families (389 identical or monozygotic (MZ) and 531 nonidentical or dizygotic (DZ)) correlated eye colour in the two groups of twins from Queensland. Statistical modelling suggested $74 \%$ of variability of this quantitative trait locus (QTL) was due to a dominant genetic factor (OCA2), 18\% additive genetic factors (polygenic/other genes) and $8 \%$ unique environmental factors [18]. The same study then conducted a genome scan using 382 autosomal and $18 \mathrm{X}$-chromosomal markers at an average spacing of $9.1 \mathrm{cM}$ on a subset of the twins, Using linkage analysis, a microsatellite marker on chromosome $15 q$ (D15S1002) was identified that was $\angle 1 \mathrm{cM}$ telomeric of the OCA2 gene with a statistical lod of 19.2, which is highly significant. No other gene region met the statistical cut-off of LOD 3. LOD or log of the odds is a statistic used in genetic linkage analysis and the usual cut-off when using several hundred markers in a linkage study (similar to a $P$ value of 0.5 ) was 10 to the power minus 3 or $1 / 1000$.

A subsequent study looked at this region in more detail using single nucleotide polymorphisms (SNPs) markers in 3839 adolescent twins, their siblings and their parents [19]. The highest association for blue/non-blue eye colour was found with three OCA2 SNPs: rs7495174 T/C, rs6497268 G/T and rs11855019 T/C in intron 1 of OCA2. These three SNPs are in one major haplotype block, with TGT representing $78.4 \%$ of alleles. The TGT/TGT diplotype found in $62.2 \%$ of samples was the major genotype seen to modify eye colour, with a frequency of 0.905 in blue or green compared with only 0.095 in brown eye colour. A three-SNP haplotype in intron 1 of OCA2 explains most human eye-colour variation. Finding a segment of chromosome where several identical markers run together in association with a disease or trait suggests that there may be an ancestral founder effect. The highest frequency for blue eyes in the population is around the Baltic Sea and this may be where the original genetic mutation originated [20]. (Fig. 9). 


\section{Multi-step Pathway for Pigment}

Black
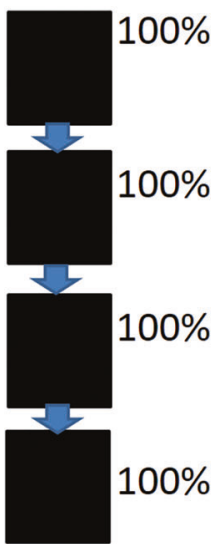

$100 \%$

$100 \%$
Albino1
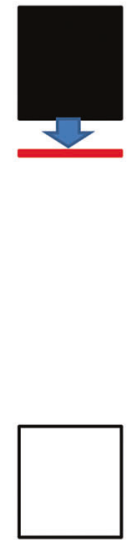

Albino2

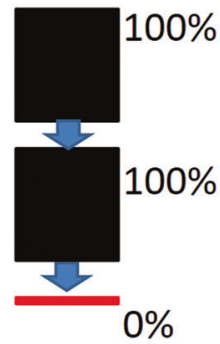

$0 \%$

$100 \%$<smiles>C1CCCCC1</smiles>

$0 \%$

$100 \%$

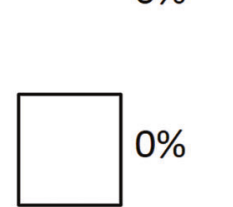

"normal child"
heterozygote

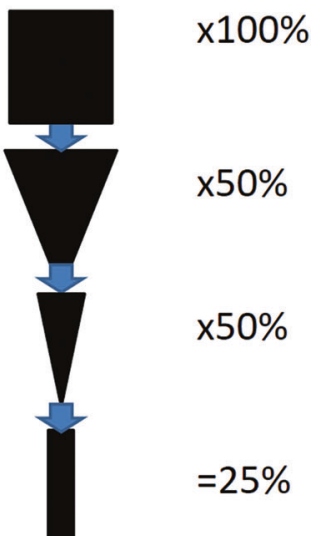

Fig. 7 A multi-step pathway for pigment shows that the production of pigment can be blocked at different steps in its production and distribution to the tissues. One parent may be recessive at the first step, while the other parent may be recessive at the second step. Thus, for each step, one of the parents does provide a "normal" copy of the gene needed and thus pigment is produced (although it may be reduced in amount).
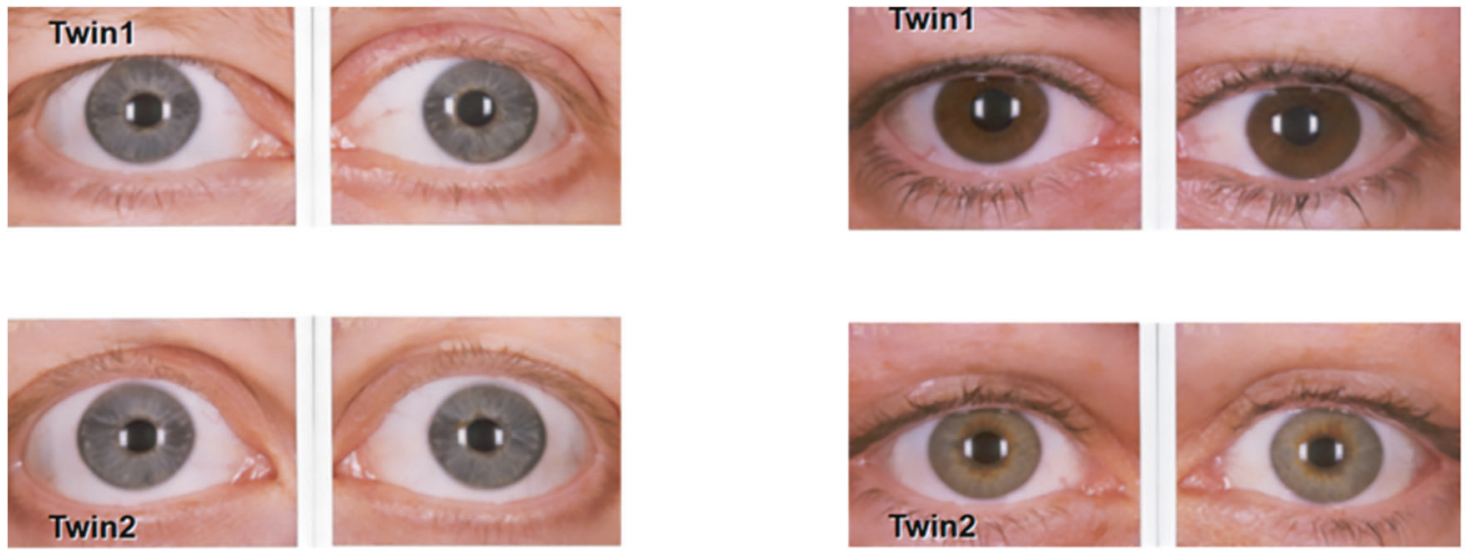

Identical

\section{Non Identical}
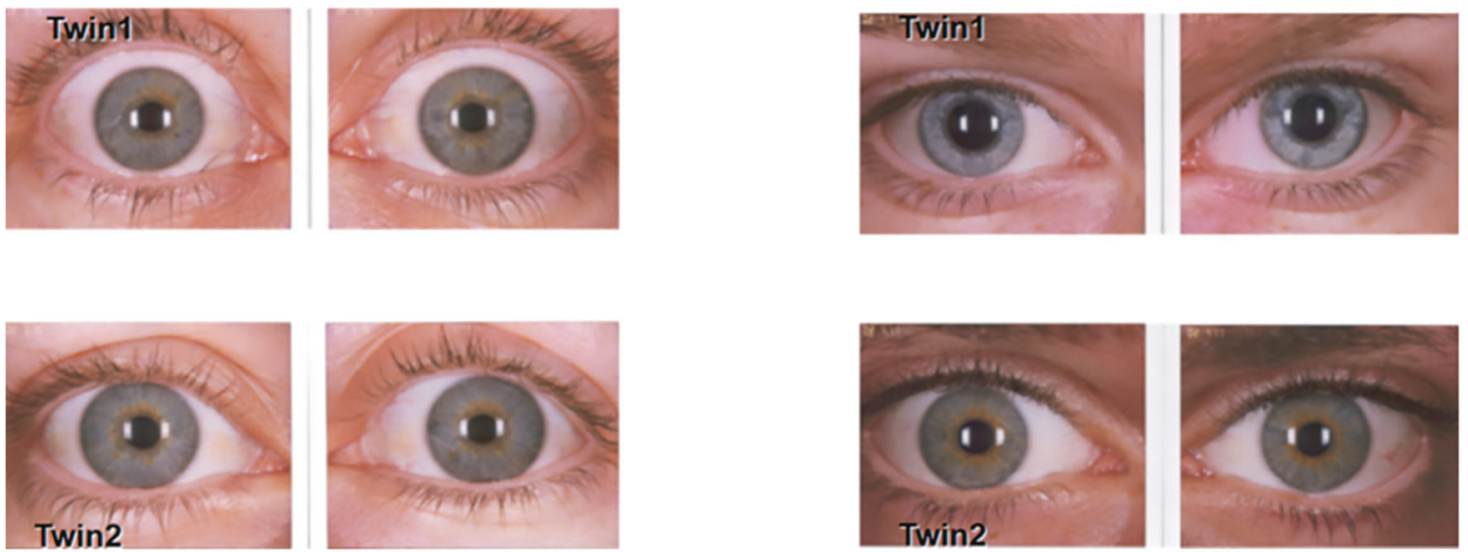

Fig. 8 Iris photos from 4 sets of twins; two sets of identical twins on the left and two sets of non-identical twins on the right. Note the increased similarity of eye colour in the identical twins. 
An observation on frequency of eye colour from the Twins Eye Study in Tasmania and Brisbane showed there were more pale blue-eyed people in higher latitude Tasmania compared to subtropical Queensland, suggesting blue-eyed (and fair-skinned) immigrants may have chosen to avoid the sun [21] (Fig. 10).

\section{Genome-wide association studies (GWAS) for eye colour}

With the development of DNA SNP markers, we were able to move from genome-wide scans of hundreds of DNA markers to hundreds of thousands of DNA markers and thus identify many more genes associated with disease. Because we are looking at so many SNPs at the same time, the statistical significance values in GWAS studies were thus higher than previous linkage studies with 10 to the power minus 8 being the usual cut off. In addition, larger studies became available, and researchers could combine their studies in larger meta-analyses. GWAS on 5951 Europeans from the Rotterdam Study identified three new regions, 1q42.3, $17 q 25.3$, and $21 \mathrm{q} 22.13$, with the latter two loci replicated in 2261 individuals from the UK and in 1282 from Australia: [14] the LYST gene at $1 \mathrm{q} 42.3$ and the DSCR9 gene at $21 \mathrm{q} 22.13$. In addition, nine previously identified genes (HERC2/OCA2, SLC2A4, TYR, TYRP1, SLC45A2, IRF4, NPLOC4, KITLG, MC1R) were linked.

An even bigger GWAS study in almost 195,000 individuals from 10 populations identified a further 50 previously unidentified genetic loci for eye colour [22]. (Fig. 11) These genes included those involved in melanin pigmentation, but there were also associations with genes involved in iris morphology and structure. Further analyses in 1636 Asian participants from two populations suggest that iris pigmentation variation in Asians is genetically similar to Europeans, but with smaller effect sizes. The currently identified genes explain just over $50 \%$ of eye colour variation using common SNPs. The genetic complexity of human eye colour considerably exceeds previous knowledge and expectations, highlighting eye colour as a genetically highly complex human trait. In terms of genetic epidemiology, we are more certain that $O C A$ is associated with blue eyes than any other gene and trait $(-\log 10(p)=43,740)$ Hysi personal communication.

Utility of understanding the genetic architecture of iris colour The application of these genetic data is particularly useful in forensic and anthropological work, where the eye colour of individuals can be predicted based on DNA evidence. Researchers have inferred that early Neolithic Britons had brown eyes, and that the famous Cheddar Man probably had blue/green eyes, with dark brown (possibly black) hair and dark or dark to black skin [23]. Eye colour is also a risk factor for eye disease; however, researchers can make interesting associations that are more linked to behaviours than genetics such as the gene for blue eyes is common in people who are bad at using chopsticks [24].

\section{ENVIRONMENTAL FACTORS INFLUENCING EYE COLOUR Eye colour change with age (but this could still be genetic)} The twin studies showed that some environmental factors are associated with eye colour [18]. There is surprisingly little published data on change in eye colour with age. Parents are aware that babies' eyes can darken in the first years of life. The Newborn Eye Screening Test study in California [25] enrolled 202 newborns, of whom 148 were followed up $(73 \%$ of parents responded at the 2-year follow-up). Brown was the most common iris colour (52.0\%) and was less likely to change over time compared to non-brown iris colours (brown to brown, 94\%, 73/ 77). There was a higher frequency of change from blue to nonblue iris colours (blue to brown $27 \%, 11 / 40$, blue to hazel $7.5 \%, 3 /$ 40 and blue to green $5 \%, 2 / 40 ; p<0.001$ ). Regarding race, at birth, the prevalence of blue irides was significantly higher among White/Caucasian, Native Hawaiian or Pacific Islander, indicating a significant difference in distribution of iris colour between races.
Iris colour did not change over the 2-year follow-up period in most cases $(66.9 \%)$, and only the iris colour of $3.4 \%(5 / 148)$ of participants became lighter from brown to hazel/green, from partial heterochromia to blue and from complete heterochromia to blue.

The Louisville Twin Study [26] ( $n=1513$ individuals) found there was a high degree of concordance in eye colour among identical (MZ) twin pairs, $(r=0.98[P<0.001])$, while the concordance was less pronounced in fraternal (DZ) twin pairs $(r=$ $0.49)$ and decreased with age $(r=0.07)$. Eye colour stabilises by 6 years of age in most children but continued to change throughout adolescence and until adulthood in a subpopulation of $10-20 \%$ of twins. This suggests that such changes in eye colour, or the propensity to such changes, may be genetically determined. As people age, changes in colour can occur, possibly best exemplified by Sharbat Gula "The Afghan Girl" photographed by Steve McCurry in 1984 and again in 2002 for National Geographic.

\section{Eye colour change with disease}

Several diseases are associated with loss of pigment, which is most obvious when only one eye is affected. Changes in iris colour may reveal signs of pathology such as neurofibromatosis, Down syndrome, herpes simplex, pigment dispersion, albinism or primary melanocytic tumours of the iris [7]. Horner syndrome occurs with sympathetic nerve damage to the eye lacking pigment, having a smaller pupil and a drooping lid. Eye Injuries can affect the pupil dilation and the iris pigmentation. A striking example was singer David Bowie. Inflammation from infections such as Fuchs Heterochromic Cyclitis or Herpes Simplex Iritis can result in loss of pigmentation. Naevi, melanomas, and Lisch nodules can increase pigment in lighter eyes while Brushfield spots in some normal people and people with Down syndrome can add white patches to the iris. The interest in loss of eye colour was another aspect of the HBO series Game of Thrones: Eddison Tollett: "Stay back, he's got blue eyes!" Tormund: "I've always had blue eyes!" From Game of Thrones-Season 8 Episode 1: 'Winterfell'

\section{Colour perception and Daltonism}

Young-Helmholz Theory of Trichromatic Colour Vision is explained by three colour opsins present in the cone cells: Red/ Long on the distal end (telomere) of the X-chromosome, Green/ Medium also on $\mathrm{X}$ and the Blue Short on chromosome 7.

Before the rise of oxygen-producing bacteria, 3750-2500 million years ago, the atmosphere was nitrogen and carbon dioxide, and so the sky possibly apeared orange. 543-490 million years ago the early Cambrian Explosion saw mass diversification of complex organisms over a relatively short period of time. There was an "evolutionary arms race driven by colour vision". Modern mammals, evolved after the dinosaur extinction, were mainly nocturnal and did not need colour vision [27]. Humans, apes and Old World monkeys are trichromatic [28]. Why do primates have colour vision? It is thought to be advantageous for the long-range detection of either ripe fruits or young leaves, which frequently flush red in the tropics, and are a critical food resource when fruit is scarce [29].

Dalton, the famous chemist, described his own colour blindness in 1794 [30]. Like his brother, he confused scarlet with green and pink with blue. He thought that his vitreous humour was tinted blue, selectively absorbing longer wavelengths. He instructed that his eyes should be examined after his death, but the examination revealed that the humours were perfectly clear. DNA was later extracted from his preserved eye tissue, showing that Dalton was a deuteranope, lacking the middle wave photopigment of the retina. This diagnosis is shown to be compatible with the historical record of his phenotype, although it contradicts Thomas Young's belief that Dalton was a protanope [31]. In 1876, Horner gave the first scientific analysis of the hereditary transmission of Daltonism. 


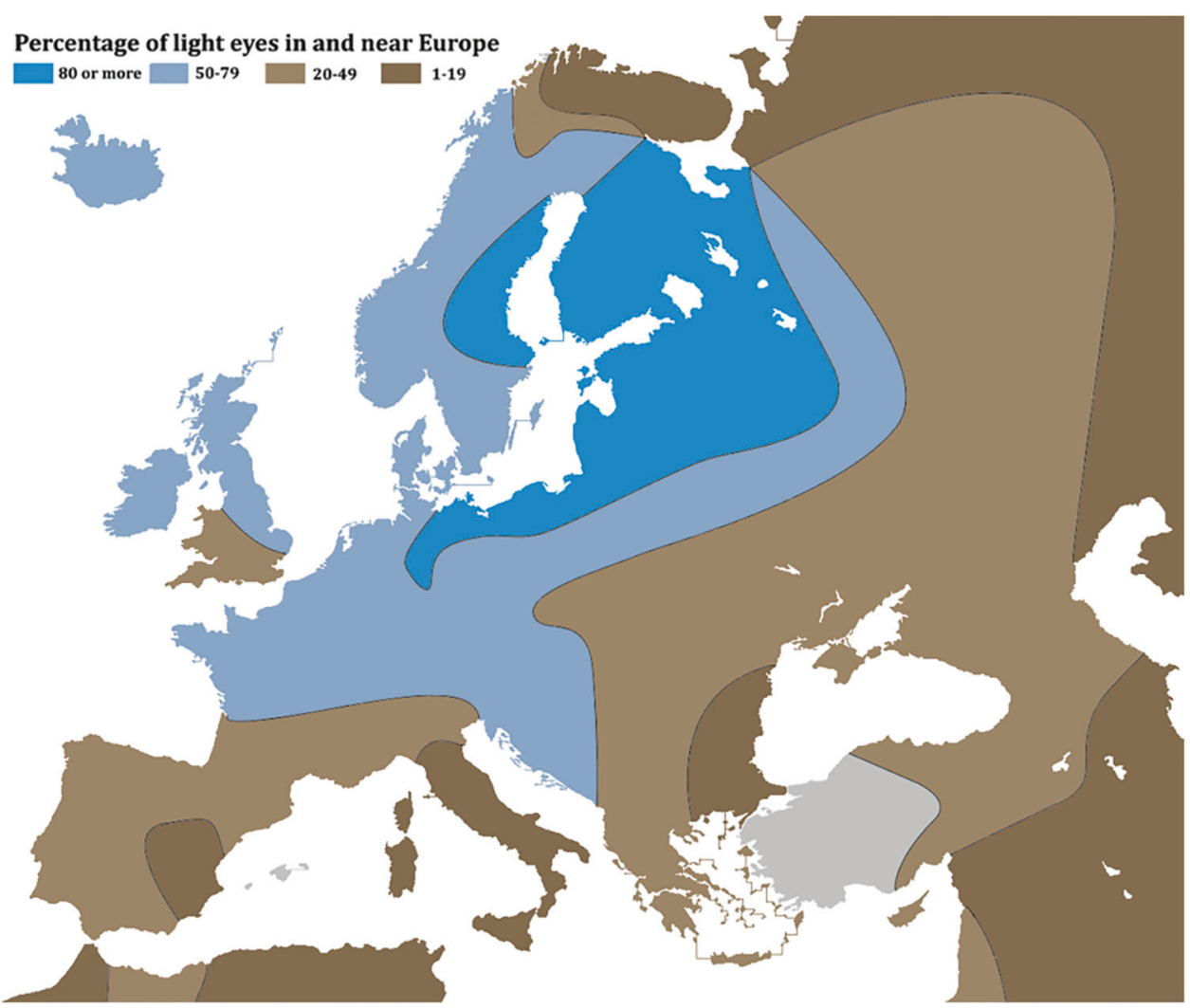

Fig. 9 Percentage of light-coloured eyes in Europe. Blue eyes are most common around the Baltic Sea. (creative commons Robert Frost) (https://commons.wikimedia.org/wiki/File:Eye_colors_map_of_Europe.png\#filelinks).

QLD

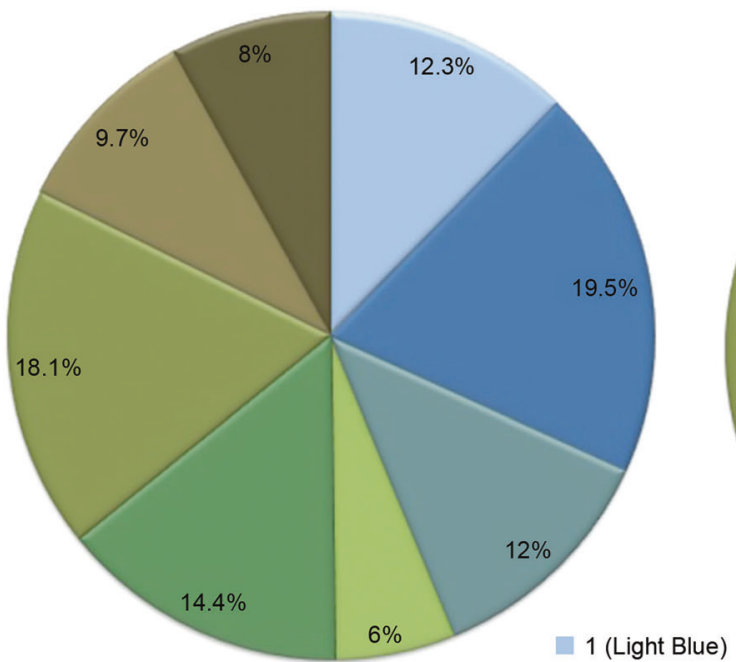

2 (Darker Blue)

3 (Blue with Brown Pupil Ring)

4 (Green)

5 (Green with Brown Iris Ring)

6 (Peripheral Green Central Brown)

7 (Brown with some Peripheral Green)

8/9 (Brown/Dark Brown)

Fig. 10 Pie charts showing frequencies of different eye colours from the Twins Eye Study in Queensland and Tasmania. Relative frequencies of different eye colours are shown, with Tasmania having more light blue eyes. 


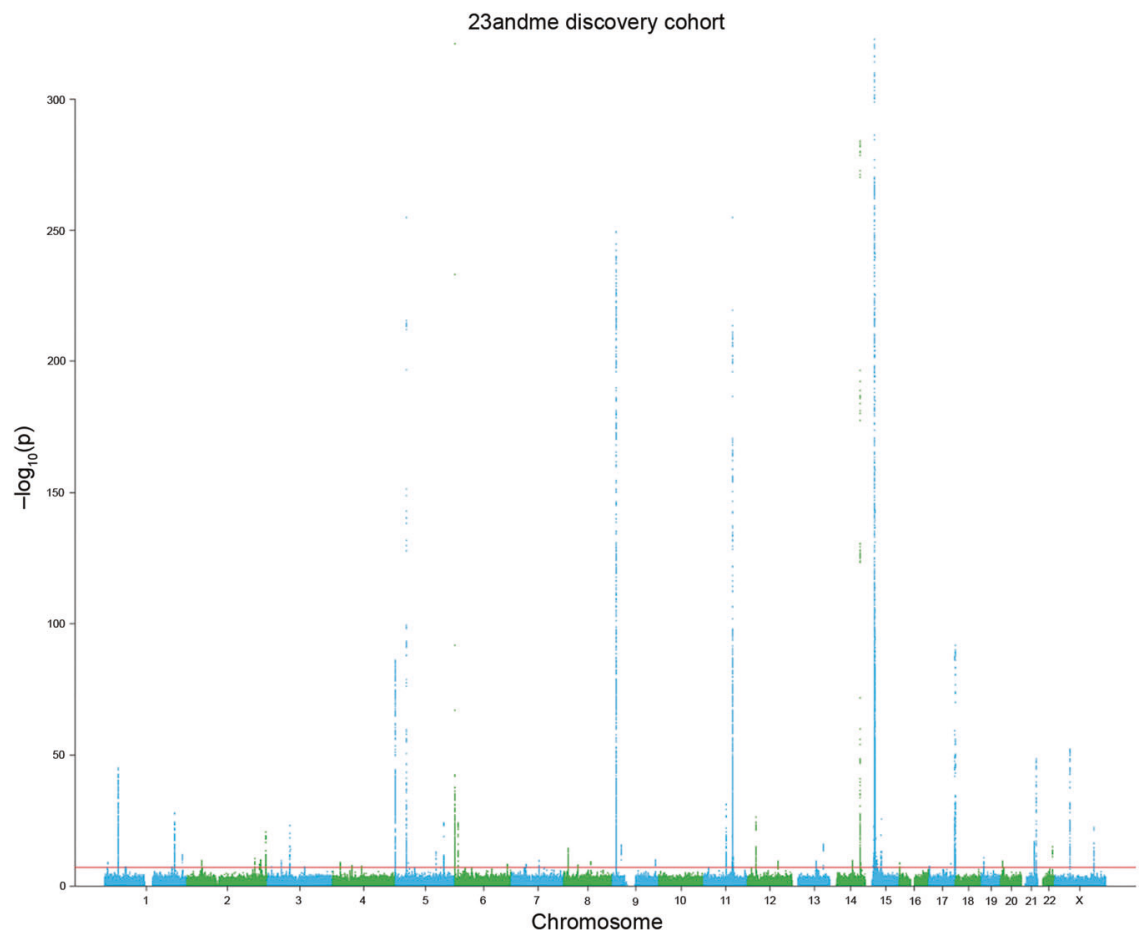

Fig. 11 A Manhattan plot for GWAS of eye colour. Each SNP in the study is shown in relation to its chromosomal location on the $X$-axis and the $p$ value on the $Y$-axis. The $p$ values $>8$ are statistically significant, with some highly significant genes resembling Manhattan skyscrapers. Image provided by Mark Simcoe from data in reference [22] Simcoe et al.

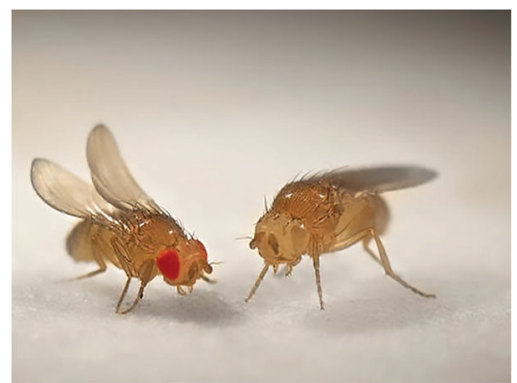

Fig. 12 Drosphila melanogaster showing red-eyed (normal) and white-eyed (mutant) variants as identified by Morgan. (creative commons Joe Jimbo) (https://theconversation.com/animals-inresearch-drosophila-the-fruit-fly-13571).

'Horner's law' says that colour-blind fathers have colour-normal daughters; and these colour-normal daughters are the mothers of colour-blind sons. In one pedigree, colour blindness is transmitted from the grandfather to the grandson. In a second pedigree, transmission was possible via female carriers through more than one generation. The similarity with the inheritance of haemophilia was mentioned by Horner [32].

\section{X-linked inheritance was discovered from eye colour in fruit flies}

Although Mendel published his work in 1866, it wasn't rediscovered until 1900, and then it only described dominant and recessive inheritance. It was American geneticist Morgan in 1910, working on fruit flies (Drosphila melanogaster), who first described sex linkage [33]. The phenotype of interest was the colour of the eyes! Instead of the normal brilliant red eyes of wild type Drosophila, he identified a fly with white eyes [34] (Fig. 12 [35]).

He performed a test cross between the white-eyed male fly and several purebred, red-eyed females to see whether white eyes occurred in the next generation. The resulting F1 generation all had red eyes; however, Morgan suspected that the white-eye trait was still present but unexpressed in this hybrid generation, like a recessive trait would be. To test this, Morgan then crossed males and females from the F1 generation and observed a 3:1 ratio of red eyes to white eyes in the F2 generation. This result is very similar to those reported for breeding experiments for recessive traits, as first shown by Mendel. However, all the white-eyed F2 flies were male, just like their grandfather-there were no white-eyed females at all! Morgan would be the first person to link definitively the inheritance of a specific trait with the X-chromosome. The mutations for white eye in drosophila is due to $A B C$ transporters that determine eye colour [36].

\section{$X$-Linked recessive inheritance}

Men have only one X-chromosome and thus if the X-chromosome carries a mutation, the man will be affected. His daughter will be an obligate carrier, inheriting the mutation from the father but having normal colour vision if she inherits a normal X-chromosome from the mother. The father's sons only inherit the X-chromosome from their mother, so cannot inherit an X-linked disease from their father. (Maleto-male transmission of a trait is usually regarded as a way of excluding X-linkage). The carrier daughters will have half their sons affected and half their daughters affected. Given that colour blindness (combining the main subgroups of protanopia, protanomaly, deuteranopia and deuteranomaly) affects around $8 \%$ of men (and $8 \%$ of women are carriers), then occasionally an affected male and a carrier female will produce an affected daughter $(8 \% \times 8 \%=$ $0.64 \%$ of women) (Fig. 13).

\section{X-inactivation}

In 1961, Lyon described the hypothesis that one of the two $X$ chromosomes of the female is inactivated at an early stage of embryogenesis or X-inactivation. Thus, in X-linked female carriers of colour blindness (and of many other X-linked retinal diseases such as retinitis pigmentosa or choroideraemia), the retina is normally a mosaic of normal and colour anomalous 


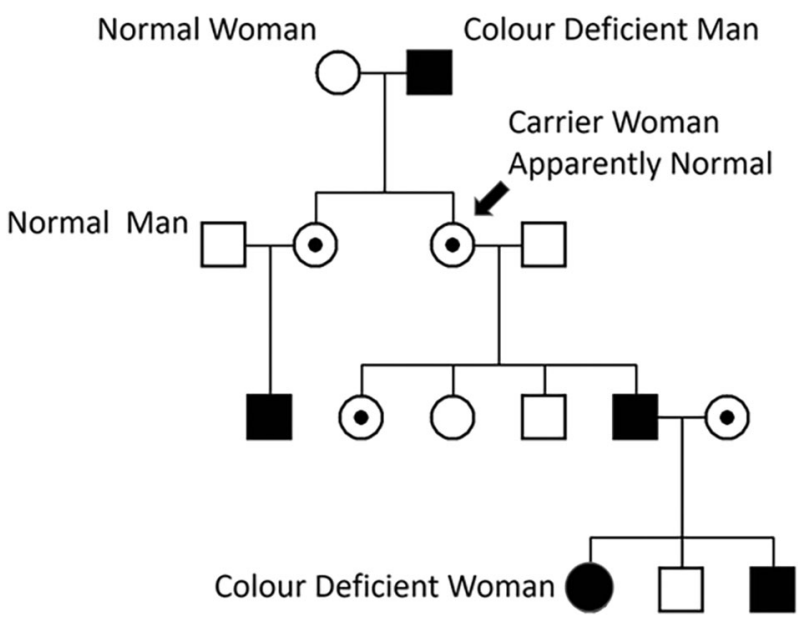

Fig. $13 \mathrm{X}$-linked pedigree showing transmission of colour blindness. Affected males are dark-coloured square, while obligate carrier females as shown as centre-filled circles and affected females as dark full circles.

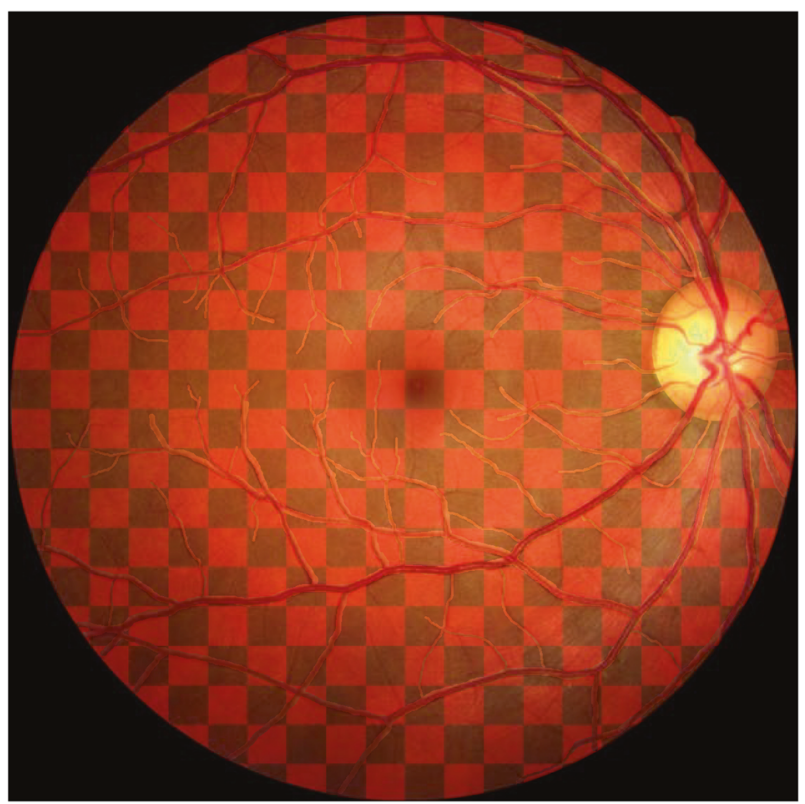

Fig. 14 Retinal image with checkerboard patchwork simulating carrier female protanope. These would be less geometrically shaped in real life. Areas in black would perceive a red light as black (protanopic from affected father or carrier mother) while areas in red would perceive red light as red (normal tritanope from normal parent).

X-chromosome expression. If one passes a coloured laser across the retina, a carrier female may notice a change in colour as the light moves across the mosaic of normal and colour-blind regions (Fig. 14). Rarely, X-inactivation can occur very early and the entire retina expresses the chromosome of only one parent. There are dozens of cases of identical MZ female twins, one of whom is colour blind and the other has normal colour vision [37]. This is an example of epigenetics (methylation) where other modifiers influence the expression of a phenotype and this occurs in many other autosomal diseases.
Telomeric location of the long (red) and medium (green) opsin allows duplication and rearrangement

The $L(O P N 1 L W)$ and $M(O P N 1 M W)$ opsins are located at the end of the long arm of the X-chromosome (Xq28). These very similar genes evolved from duplications of a single gene and subsequent mutations and cross-over events creating hybrid genes to a selection of genes, each with different peak spectral sensitivity. Alterations in the cone opsin genes underlie inherited colourvision deficiencies. Among individuals with normal colour vision, there is variability in the number or homology of photo-pigment genes and their arrangement in a tandem array allows for a high mutation rate (Fig. 15). Many of the genotypes associated with colour-vision deficiencies are the result of a series of mutational steps away from ancestral gene arrays [38]. Polymorphisms in the $L$ and $M$ opsins give slight differences in spectral sensitivity. Blue cone monochromacy occurs when all the $X$ chromosoma opsins are missing. Other genes also affect the expression of the opsins and the array of the L, M and S photoreceptors [39].

\section{Variation on rates of colour blindness in men}

Some populations, such as the Australian Aborigines, have low rates of red-green colour blindness on Ishihara testing (1.6\%), in contrast to $37 / 503$ (7.4\%) Europeans in Western Australian regional areas, with similar low rates in Papuans (2\%) and Fijians $(0.8 \%)$ [40]. Why are so many men colour "blind" [41] in most populations? Although well known by the military, there is surprisingly little published information on the ability of colourblind men to see through camouflage [41]. We conducted a study in Australia showing that pairing people with normal colour vision with those who were colour-blind gave the best results in a search and rescue training exercise [42]. Thus, it is possible that groups of men hunting that included some who were colour blind and some who had normal colour vision may have had a survival advantage for hunter gatherers. A red rag to a bull would appear black. There are some clever adaptations to using colour blindness in pets, such as cats wearing brightly coloured collars that can be used to protect native birds [43].

\section{\#The Dress}

On 27 Feb 2015, a picture of a dress went viral on social media after Celia Bleasdale sent her daughter Grace of Colonsay, Scotland, a photo of a black and blue dress she was going to buy Fig. 16. "That's lovely mum. The gold and white one." Celia's partner also saw the photo as white and gold-even though he had seen the original dress. The daughter shared the picture on Facebook and on February 26, 2015, a friend Caitlin McNeil reposted it on Tumblr, which was noted by Buzzfeed. Buzzfeed got 39 million hits; Tumblr was getting 840,000 views a minute; Twitter had 11,000 tweets per minute! A significant proportion of the population saw it as golden and white, while another significant proportion saw it as blue and black. \#The Dress that alerted the world to colour, colour perception and human variation launched over 25 journal articles ranging from explanations of the concept of colour constancy through to genes and environmental experiences [44-66]. Although colour constancy is certainly involved, there is still no theory available to explain the dichotomous character of this optical illusion. Assumptions about the illumination of the dress-i.e. whether the stimulus was illuminated by natural or artificial light or whether it was in a shadow-strongly affects the subjective interpretation of observers [62]. The perception of colours is guided by the scene interpretation and the inferred positions of light sources. People who perceive the dress as blue-and-black are two times more likely to consider the light source coming from the front than those who see the white-and-gold dress. Participants' environmental lighting conditions are an important cue for perceiving the dress colours [46]. 
$\begin{array}{llll}\text { Telomere } & \mathrm{p} \text { (short) arm } & \text { Centromere } & \text { q long) arm }\end{array}$

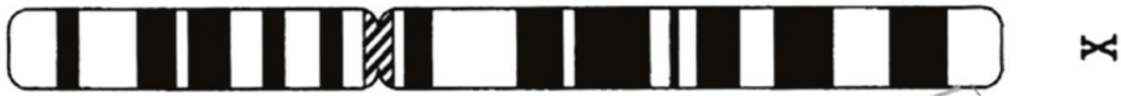

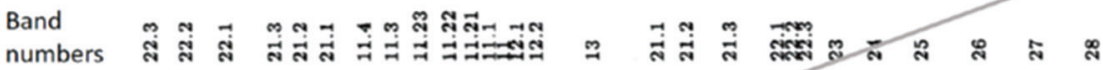

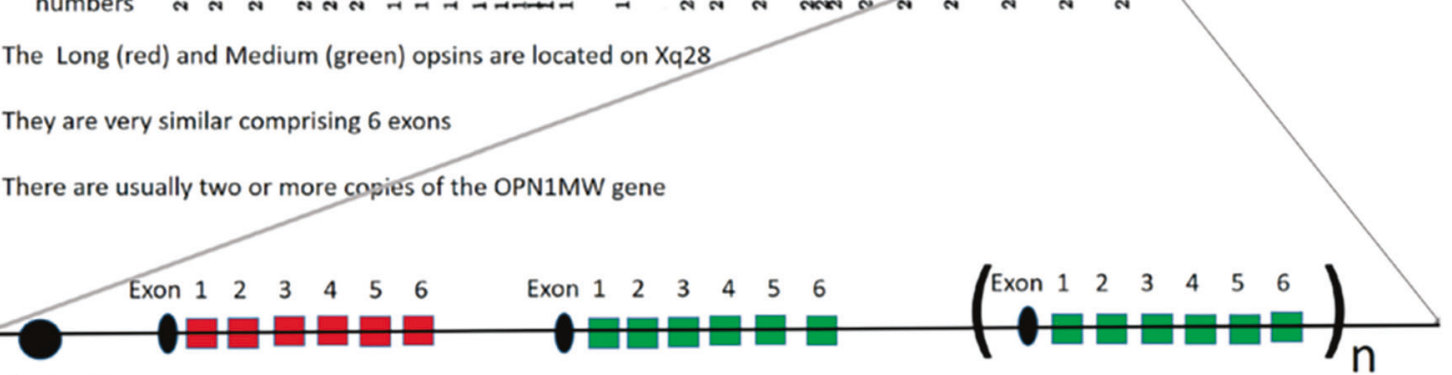

Opsin LCR

Locus

OPN1LW

OPN1MW

more copies of OPN1MW

Control

Region

Numerous variations of the amino acids in the exons give different spectral sensitivity

Fig. 15 Diagram with location of the colour opsins on the $X$ chromosome. Above a banded $X$ chromosome showing the location of the red (OPN1LW) and green (OPN1MW) opsins in tandem on the telomere of the X-10.1038/s41433-021-01749-X chromosome. Below a OPN1LW gene comprised of 6 exons followed by two OPN1MW genes comprised of 6 exons.

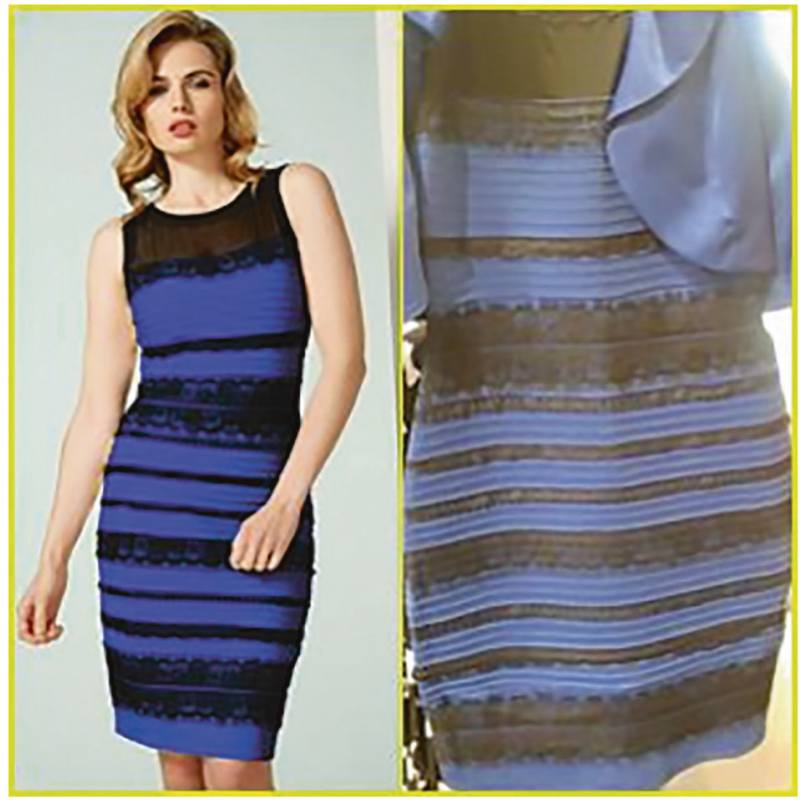

Fig. 16 \#The Dress of viral internet fame. Actual colour black and blue on the left and the ambiguous image perceived as white and gold or black and blue on the right.

Researchers at 23andMe conducted an instant genetics experiment by asking customers, who have consented to research, about what colours they saw looking at that dress and about 25,000 people responded [67]. The colours seen in those stripes are influenced by the age of the viewer and where the viewer grew up. Those individuals 20 years of age were split evenly between white $\&$ gold vs. blue \& black, with the proportion seeing white $\&$ gold increased up until the age of 60 years (75\%). Those who grew up in more urban areas saw white and gold at higher proportions than those who grew up in more rural areas. 23andme found no clear genetic association with seeing either a blue $\&$ black dress vs. seeing a white $\&$ gold one. A small effect size was noted for a genetic variant in the gene ANO6, a member of the anoctamins gene family that includes the gene ANO2 (expressed in the retina and several brain regions), which is "involved in light perception". Identical twins also reported seeing different colours. The British TwinsUK registry found MZ twins were more concordant in their responses than DZ twins $(0.46 \mathrm{vs}$. 0.36). Twin modelling revealed that genetic factors accounted for $34 \%$ of variation in the reported colour of the dress when adjusted for age, whereas environmental factors contributed 66\% [57]. Eye conditions did influence the colour perception: individuals with cataracts were about $50 \%$ more likely to see black \& blue instead of white \& gold; individuals who were colour-blind were more likely to see white $\&$ gold but age-related macular degeneration appeared to have no influence. A person's initial impression of the dress colour was likely to stick. The Dress image illustrates the complex interaction between both our genetics and environment.

\section{CONCLUSION}

\section{Colour is in the eye of the beholder}

What colour are your partner's eyes? (Please proceed with caution as not all people give the right answer!) Eye colour and colour perception are very good examples to teach the general population about basic genetic (Dominant, Recessive and Xlinked) as well as more complex genetics including: polygenic inheritance, gene duplications and deletions. epigenetics, linkage, genome-wide association studies, founder effects and evolution. Genetics is involved in all the leading eye diseases, not just Inherited Retinal diseases and congenital abnormalities but also the leading causes of blindness: age-related macular degeneration, glaucoma, myopia, diabetic retinopathy and cataract. A good working knowledge of genetics should be part of the clinical skills of every practicing ophthalmologist. We need to ask every patient with any eye disease if they have a family history. "Does anyone else in the family have....?" In the near future asymptomatic patients will attend eye clinics with genetic results that show they are at high risk of certain eye diseases and ophthalmologist will need to know how to screen and follow these patients. Genomics, big data and artificial intelligence will be driving this research in the coming years. We need to equip everyone to understand and 
utilise this revolution of information by understanding genetics better. From this we will deliver even better outcomes to eradicate blindness and vision impairment.

\section{REFERENCES}

1. McKusick V. Mendelian Inheritance in Man: Catalogs of autosomal dominant, autosomal excessive, and x-linked phenotypes. Baltimore:Johns Hopkins Press;1966.p. 344.

2. Berlin B, Kay P. Basic color terms: their universality and evolution. Univ of California Press; Berkeley and Los Angeles, California 1991.

3. Fisher L. Perceptual thresholds: music inspired Newton's rainbow. Nature. 2015;520:436.

4. Smith T, Guild J. The CIE colorimetric standards and their use. Trans Optical Soc. 1931;33:73.

5. Wikipedia colors wikipedia.org/wiki/Web_colors.

6. Pantone colours http://www.pantone-colours.com.

7. Mackey DA, Wilkinson CH, Kearns LS, Hewitt AW. Classification of iris colour: review and refinement of a classification schema. Clin Exp Ophthalmol. 2011;39:462-71.

8. Brownlee J. XXXI.-On Inheritance of Hair and Eye Colour. Proc R Soc Edinb. 1913:32:458-74.

9. Cornaz É. Recherches statistiques sur la fréquence comparative des couleurs de I'iris publisher Ghent University, place of publication Ghent, Belgium 1860.

10. Galton FI. Family likeness in eye-colour. Proc R Soc Lond. 1886;40:402-16.

11. Petrequin J. Sur les diverses couleurs de l'iris et leurs proportions dans nos climats. Ann d'oculistique. 1843;10:120-5.

12. Tocher JF. Pigmentation survey of school children in Scotland. Biometrika 1908; 6 : 129-235.

13. Wilde WR. An essay on the malformations and congenital diseases of the organs of sight. Dublin: John Churchill;1862.

14. Liu F, Wollstein A, Hysi PG, Ankra-Badu GA, Spector TD, Park D, et al. Digital quantification of human eye color highlights genetic association of three new loci. PLoS Genet. 2010;6:e1000934.

15. Larsson M, Duffy DL, Zhu G, Liu JZ, Macgregor S, McRae AF, et al. GWAS findings for human iris patterns: associations with variants in genes that influence normal neuronal pattern development. Am J Hum Genet. 2011;89:334-43.

16. Rare diseases: LHON. https://rarediseases.org/rare-diseases/leber-congenitalamaurosis.

17. Sanfilippo PG, Hewitt AW, Hammond CJ, Mackey DA. The heritability of ocular traits. Surv Ophthalmol. 2010;55:561-83.

18. Zhu G, Evans DM, Duffy DL, Montgomery GW, Medland SE, Gillespie NA, et al. A genome scan for eye color in 502 twin families: most variation is due to a QTL on chromosome 15q. Twin Res. 2004;7:197-210.

19. Duffy DL, Montgomery GW, Chen W, Zhao ZZ, Le L, James MR, et al. A threesingle-nucleotide polymorphism haplotype in intron 1 of OCA2 explains most human eye-color variation. Am J Hum Genet. 2007;80:241-52.

20. Frost P. European hair and eye color: a case of frequency-dependent sexual selection? Evol Hum Behav. 2006;27:85-103.

21. Sanfilippo PG, Wilkinson CH, Ruddle JB, Zhu G, Martin NG, Hewitt AW, et al. Don't it make your brown eyes blue? A comparison of iris colour across latitude in $A$ ustralian twins. Clin Exp Optom. 2015;98:172-6.

22. Simcoe M, Valdes A, Liu F, Furlotte NA, Evans DM, Hemani G, et al. Genome-wide association study in almost 195,000 individuals identifies 50 previously unidentified genetic loci for eye color. Sci Adv. 2021;7:eabd1239.

23. Brace S, Diekmann Y, Booth TJ, van Dorp L, Faltyskova Z, Rohland N, et al. Ancient genomes indicate population replacement in Early Neolithic Britain. Nat Ecol Evol. 2019;3:765-71.

24. Hamer D, Sirota L. Beware the chopsticks gene. Mol Psychiatry. 2000;5:11-3.

25. Jabbehdari S, Sinow C, Ludwig CA, Callaway NF, Moshfeghi DM. Colour change in the newborn iris: 2-year follow-up of the Newborn Eye Screening Test study. Acta Ophthalmol. 2020;98:e521-e2.

26. Bito LZ, Matheny A, Cruickshanks KJ, Nondahl DM, Carino OB. Eye color changes past early childhood. The Louisville Twin Study. Arch Ophthalmol. 1997;115:659-63.

27. Maor R, Dayan T, Ferguson-Gow H, Jones KE. Temporal niche expansion in mammals from a nocturnal ancestor after dinosaur extinction. Nat Ecol Evol. 2017;1:1889-95.

28. Yokoyama S, Xing J, Liu Y, Faggionato D, Altun A, Starmer WT. Epistatic adaptive evolution of human color vision. PLoS Genet. 2014;10:e1004884.

29. Dominy NJ, Lucas PW. Ecological importance of trichromatic vision to primates. Nature. 2001;410:363-6.

30. Dalton J. Extraordinary facts relating to the vision of colours: with observations. Memoirs of the Literary and Philosophical Society of Manchester, 1798;5:28-45.
31. Hunt DM, Dulai KS, Bowmaker JK, Mollon JD. The chemistry of John Dalton's color blindness. Science. 1995;267:984-8.

32. Jaeger W. Horner's law. The first step in the history of the understanding of X-linked disorders. Ophthalmic Paediatr Genet. 1992;13:49-56.

33. Miko I. Thomas Hunt Morgan and sex linkage. Nat Educ. 2008;1:143.

34. Morgan TH. The origin of five mutations in eye color in Drosophila and their modes of inheritance. Science. 1911;33:534-7.

35. Jimbo J. Reproduced from The Conversation (Animals in research: Drosophila [the fruit fly]) April 2013. https://theconversation.com/animals-in-research-drosophilathe-fruit-fly-13571.

36. Mackenzie SM, Brooker MR, Gill TR, Cox GB, Howells AJ, Ewart GD. Mutations in the white gene of Drosophila melanogaster affecting $A B C$ transporters that determine eye colouration. Biochim Biophys Acta. 1999;1419:173-85.

37. Tiberio G. MZ female twins discordant for X-linked diseases: a review. Acta Genet Med Gemellol (Roma). 1994;43:207-14.

38. Neitz J, Neitz M. The genetics of normal and defective color vision. Vis Res. 2011;51:633-51.

39. Haider NB, Jacobson SG, Cideciyan AV, Swiderski R, Streb LM, Searby C, et al. Mutation of a nuclear receptor gene, NR2E3, causes enhanced $\mathrm{S}$ cone syndrome, a disorder of retinal cell fate. Nat Genet. 2000;24:127-31.

40. Mann I, Turner C. Color vision in native races in Australasia. Am J Ophthalmol. 1956;41:797-800.

41. Morgan MJ, Adam A, Mollon JD. Dichromats detect colour-camouflaged objects that are not detected by trichromats. Proc Biol Sci. 1992;248:291-5.

42. Crewe JM, Brown H, Fyfe D, Mackey DA. Does including colour-blind men enhance search and rescue teams? Clin Exp Ophthalmol. 2018;46:817-8.

43. Hall CM, Fontaine JB, Bryant KA, Calver MC. Assessing the effectiveness of the Birdsbesafe ${ }^{\circledast}$ anti-predation collar cover in reducing predation on wildlife by pet cats in Western Australia. Appl Anim Behav Sci. 2015;173:40-51.

44. Aston S, Hurlbert A. What \#theDress reveals about the role of illumination priors in color perception and color constancy. J Vis. 2017;17:4.

45. Brainard DH, Hurlbert AC. Colour Vision: Understanding \#TheDress. Curr Biol. 2015;25:R551-4.

46. Chetverikov A, Ivanchei I. Seeing "the Dress" in the Right Light: Perceived Colors and Inferred Light Sources. Perception. 2016;45:910-30.

47. Dixon EL, Shapiro AG. Spatial filtering, color constancy, and the color-changing dress. J Vis. 2017;17:7.

48. Drissi Daoudi L, Doerig A, Parkosadze K, Kunchulia M, Herzog MH. The role of one-shot learning in \#TheDress. J Vis. 2017;17:15.

49. Feitosa-Santana C, Lutze M, Barrionuevo PA, Cao D. Assessment of \#TheDress With Traditional Color Vision Tests: perception Differences Are Associated With Blueness. Iperception. 2018;9:2041669518764192.

50. Gegenfurtner KR, Bloj M, Toscani M. The many colours of 'the dress'. Curr Biol. 2015;25:R543-4.

51. Hesslinger VM, Carbon CC. \#TheDress: The Role of Illumination Information and Individual Differences in the Psychophysics of Perceiving White-Blue Ambiguities. Iperception. 2016;7:2041669516645592.

52. Hugrass L, Slavikova J, Horvat M, Musawi AA, Crewther D. Temporal brightness illusion changes color perception of "the dress". J Vis. 2017;17:6.

53. Karlsson BS, Allwood CM. What Is the Correct Answer about The Dress' Colors? Investigating the Relation between Optimism, Previous Experience, and Answerability. Front Psychol. 2016;7:1808.

54. Kuriki I. A Novel Method of Color Appearance Simulation Using Achromatic Point Locus With Lightness Dependence. Iperception. 2018;9:2041669518761731.

55. Lafer-Sousa R, Conway BR. \#TheDress: Categorical perception of an ambiguous color image. J Vis. 2017;17:25.

56. Lafer-Sousa R, Hermann KL, Conway BR. Striking individual differences in color perception uncovered by 'the dress' photograph. Curr Biol. 2015;25:R545-6.

57. Mahroo OA, Williams KM, Hossain IT, Yonova-Doing E, Kozareva D, Yusuf A, et al. Do twins share the same dress code? Quantifying relative genetic and environmental contributions to subjective perceptions of "the dress" in a classical twin study. J Vis. 2017;17:29.

58. Schlaffke L, Golisch A, Haag LM, Lenz M, Heba S, Lissek S, et al. The brain's dress code: how The Dress allows to decode the neuronal pathway of an optical illusion. Cortex. 2015;73:271-5.

59. Toscani M, Gegenfurtner KR, Doerschner K. Differences in illumination estimation in \#thedress. J Vis. 2017;17:22.

60. Uchikawa K, Morimoto T, Matsumoto T. Understanding individual differences in color appearance of "\#TheDress" based on the optimal color hypothesis. J Vis. 2017;17:10.

61. Vemuri K, Srivastava A, Agrawal S, Anand M. Age, pupil size differences, and color choices for the "dress" and the "jacket". J Opt Soc Am A Opt Image Sci Vis. 2018;35:B347-B55.

62. Wallisch P. Illumination assumptions account for individual differences in the perceptual interpretation of a profoundly ambiguous stimulus in the color domain: "The dress". J Vis. 2017;17:5. 
63. Winkler AD, Spillmann L, Werner JS, Webster MA. Asymmetries in blue-yellow color perception and in the color of 'the dress'. Curr Biol. 2015;25:R547-8.

64. Witzel C, O'Regan JK, Hansmann-Roth S. The dress and individual differences in the perception of surface properties. Vis Res. 2017;141:76-94.

65. Witzel C, Racey C, O'Regan JK. The most reasonable explanation of "the dress": implicit assumptions about illumination. J Vis. 2017;17:1.

66. Xiao F, Cai G, Zhang H. Segregation Analysis Suggests That a Genetic Reason May Contribute to "the Dress" Colour Perception. PLoS ONE. 2016;11:e165095.

67. 23andme. Genetics and that striped dress. https://blog.23andme.com/23andmeresearch/genetics-and-that-striped-dress/.

\section{AUTHOR CONTRIBUTIONS}

This paper was written by DAM from the presentation given in Glasgow, 2019.

\section{FUNDING}

DAM is funded by an NHMRC practitioner fellowship.

\section{COMPETING INTERESTS}

The author declares no competing interests.

\section{ADDITIONAL INFORMATION}

Correspondence and requests for materials should be addressed to D.A.M.

Reprints and permission information is available at http://www.nature.com/ reprints

Publisher's note Springer Nature remains neutral with regard to jurisdictional claims in published maps and institutional affiliations.

(i) Open Access This article is licensed under a Creative Commons Attribution 4.0 International License, which permits use, sharing, adaptation, distribution and reproduction in any medium or format, as long as you give appropriate credit to the original author(s) and the source, provide a link to the Creative Commons license, and indicate if changes were made. The images or other third party material in this article are included in the article's Creative Commons license, unless indicated otherwise in a credit line to the material. If material is not included in the article's Creative Commons license and your intended use is not permitted by statutory regulation or exceeds the permitted use, you will need to obtain permission directly from the copyright holder. To view a copy of this license, visit http://creativecommons. org/licenses/by/4.0/.

(c) The Author(s) 2021 